\title{
Health Related Challenges Among Pregnant Teenagers Attending Narok County Hospital, Narok County
}

\author{
Ronald Omenge Obwoge, Annette Okere, Chamia Nduku, Hillary Koech, Celestine Muruthi, \\ Nelson Kyalo, Kevin Wanjala, Ruth Lulu
}

Department of Community Health, Egerton University, Nakuru, Kenya

Email address:

obwogeo@yahoo.com (R. O. Obwoge)

\section{To cite this article:}

Ronald Omenge Obwoge, Annette Okere, Chamia Nduku, Hillary Koech, Celestine Muruthi, Nelson Kyalo, Kevin Wanjala, Ruth Lulu. Health Related Challenges Among Pregnant Teenagers Attending Narok County Hospital, Narok County. International Journal of Gastroenterology. Vol. 3, No. 2, 2019, pp. 35-40. doi: 10.11648/j.ijg.20190302.12

Received: July 29, 2019; Accepted: December 26, 2019; Published: January 8, 2020

\begin{abstract}
Teenage pregnancy is on the rise globally especially in developing countries. There are many the health related challenges that pregnant teenagers are exposed to. Pregnant teenagers are prone to health risks that endanger themselves and unborn babies. It is important for healthcare fraternity to be informed of these the health related challenges that are associated with teenage pregnancy. The study aimed to determine the health related challenges that teenage girls visiting Narok County Hospital face. By; (1) determining the health related challenges among pregnant teenagers attending Narok County Hospital. (2) Establishing the level of awareness on modern contraceptive methods among pregnant teenage visiting $\mathrm{NCH}$. To determine health seeking behaviors among pregnant teenagers who visit $\mathrm{NCH}$ The study adopted a cross-sectional research study, Interview guide and abstraction sheets to capture data. Interview 41 respondents of whom 35 pregnant teenagers and 6 key informants. The pregnant teenagers were non-medics while the key respondents were medical personnel at different levels but who in their course of work had interacted with pregnant teenagers. The study revealed that $60 \%$ of the respondents had experienced health challenges during the course of pregnancy. Of whom majority of the pregnant teenagers had varied number of health challenges during the course of their pregnancy. These findings are quite similar to other studies that have been done globally. Study recommends a more focused antenatal profile for pregnant teenagers and community health program targeting the whole community to prevent teen pregnancies.
\end{abstract}

Keywords: Teenage Pregnancy, Health Conditions, Health Challenges

\section{Introduction}

Teenage pregnancies are a global problem that occurs in high, middle, and low income countries, globally more likely to occur in marginalized communities, commonly driven by poverty and lack of education and employment opportunities. Every year, an estimated 21 million girls aged 15 to 19 years and 2 million girls aged under 15 years become pregnant in developing regions. Approximately 16 million girls aged 15 to 19 years and 2.5 million girls under age 16 years give birth in developing regions [1].

Teenage pregnancies and teenage motherhood are a cause for concern worldwide. The prevention of teenage pregnancies and teenage motherhood is a priority for public health in nearly all developed and increasingly in developing countries [2].
Pregnant adolescents are highly vulnerable group and mental health services needs to be understood better, they have multiple needs, but there is a lack of holistic approach of service [3].

Health care during adolescence should be tailored to meet the changing developmental needs of the adolescent while providing welcoming, safe, and confidential care. Parents, educators, care providers, public health officials, and communities should collaborate in fostering healthy environments for all adolescents, now and into the future [4].

Inequitable gender norms and social norms that condone violence against women put girls at greater risk of unintended pregnancy. Pregnancy and childbirth complications are the leading cause of death among 15 to 19 year-old girls globally, with low and middle-income countries. Their Newborns born are also at greater risk of 
having low birth weight, with long-term potential effects [1].

Uganda has an adolescent fertility rate of 115 which is the highest in east Africa while Kenya has 92 and Burundi with the lowest at 29 [5].

Child bearing among teens in Narok County is at 40 percent higher than the national average of 18 percent. About 24 percent in Narok County are adolescents aged between 10 and 19 and those below 15 make up 50 percent of the population (KDHS, 2014). Every year 16 million girls between ages 15 and 19 and 1 million girls aged 14 and below give birth, 95 percent of these happen mostly in low income and middle income countries [6].

Teenage pregnancy associated factors among school adolescents and Significant predictors of teenage pregnancy among school adolescents of Arba Minch Town were; not knowing the exact time to take emergency contraceptives, substance use, living with either of biological parents and poor parent-daughter interaction [7].

Among other influencing factors Peer influence, unwanted sexual advances from adult males, coercive sexual relations, unequal gender power relations, poverty, early marriage, lack of parental counseling and guidance, parental neglect, lack of comprehensive sexuality education, non-use of contraceptives, male's responsibility to buy condoms, early sexual debut excessive use of alcohol, substance abuse, educational status, inability to resist sexual temptation, curiosity, lack of comprehensive sexuality education, misconceptions about contraceptives, and non-friendly adolescent reproductive services as influencing adolescent pregnancies in Sub-Saharan Africa [8]. Also familial factors, being married was found to increase the likelihood of teenage pregnancy. Peer pressure, sexual abuse and lack of control over sex was observed to increase the likelihood of teenage pregnancy [9]. Pregnancy prevention among the adolescents educational intervention significantly improved sexual abstinence and the knowledge of adolescents on the risk associated [10].

Early pregnancy of junior high school girls found that the effects of teenage pregnancy were numerous; included academic career- school dropout, temporal withdrawal from school and absenteeism. And contextualized factors - early marriage, single parenting, increased family burden and sexual transmitted diseases [11].

Teenage pregnancy is still a common occurrence in India. Early menarche, early age at marriage, low education, unemployment, joint family structure, lack of antenatal care has adverse impact on the health of teenage mothers leading to various adverse maternal and fetal outcome. Teenagers who get pregnant chose to abort or are married off at a very young age, due to these the government has employed measures to curb negative effects of teenage pregnancy [12].

Adolescent pregnancy and parenthood are associated with social, health and financial costs to teen parents, families and states. A teen birth can disrupt young people's educational and career goals, affecting earning potential and future family finances. Teenage mothers are also more likely to live in poverty and depend on public assistance. Children born to teen parents are more likely to have lower school achievement, drop out of high school and become teen parents themselves, compared to children born to older parents [13].

This study aimed to determine the health related challenges among pregnant teenagers visiting Narok County Hospital.

\section{Methodology}

\subsection{Study Area}

The study was conducted at Narok County, Kenya. It is estimated to be about $17,921.2 \mathrm{Km}^{2}$. The county population size is 850,920 . Narok is a commercial centre, a tourist destination and an agricultural Centre with the main crop grown in Narok being wheat.

\subsection{Study Design and Sampling Procedure}

The study adopted a cross-sectional design. The study target population was pregnant teenagers who attended the antenatal clinic and maternity ward admissions. Convenient sampling was used; hence, each pregnant teenager that came to the antenatal clinic or admitted to the maternity ward was interviewed.

\subsection{Study Population}

Interviewed were a total of 46 respondents, 35 (pregnant teenagers) and 6 (key informants comprising A social worker, a pharmacist, a clinical officer, two nurses and a medical officer).

\subsection{Inclusion and Exclusion Criteria}

The study included all pregnant women who are in their teenage years. The study excluded all teenagers not pregnant and all pregnant women that were past teenage (19) years.

\subsection{Data Collection Methods and Tools}

Data was collected through interviewing method utilizing an interview guide.

\subsection{Data Collection Procedures}

Data collected through interviews were confidential no respondents' names were not recorded. Once the teenage mothers were interviewed, their responses were written down.

\subsection{Data Analysis}

The quantitative data collected was cleaned, coded, entered and analyzed using Statistical Package for Social Sciences (SPSS) version 21. Qualitative data collected analyzed using in-depth qualitative data analysis to arrive at final written document. 


\section{Results}

\subsection{Socio-demographic Characteristics}

The study interviewed 35 respondents of whom were interviewed $2.9 \%$ (1) had no education, $42.9 \%$ (15) had primary education, $48.6 \%$ (17) had secondary education and $5.7 \%$ (2) had tertiary education. Concurring with key informants report that majority of the pregnant teenagers had either attained primary or secondary education. On marital status $68.6 \%$ (24) were single and $31.4 \%$ (11) were married. Of the married $81.8 \%$ (9) were in a monogamous and $18.2 \%$ (2) were in a polygamous marriages.

\subsection{Health Related Challenges Facing Pregnant Teenagers}

Study sought to determine determine the health related challenges that teenage girls visiting Narok County Hospital. It analyzed the health challenges and revealed that $60 \%$ (24) experienced health challenges while $40 \%$ (14) didn't experienced any health challenge during their course of pregnancy. The experienced health challenges were as indicated in table 1.

Table 1. Health challenges among Pregnant Teenagers.

\begin{tabular}{llll}
\hline \multicolumn{2}{l}{ Respondents reported } & \multicolumn{2}{l}{ Key informants' report } \\
\hline 1 & Hypertension, & 1 & Diabetes mellitus \\
2 & Anemia, & 2 & Pre-eclampsia \\
3 & Urinary tract infection (UTI) & 3 & Eclampsia \\
4 & Peptic ulcer disease (PUD), & 4 & Psychosis \\
& & 5 & Anemia \\
& & 6 & Depression \\
5 & Sexually transmitted infections & 7 & Minor paralysis \\
& (STI). & 8 & Cephalo-pelvic \\
& & 9 & disproportion \\
& & & Cervical tears \\
\hline
\end{tabular}

\subsection{Awareness on Modern Contraception Among Teenagers}

The study also sought to determine the awareness on modern contraception among teenagers. On inquiry of whether the pregnancies were intended or not. Study indicated that $25.7 \%$ (9) pregnancies were intended while $74.3 \%$ (26) pregnancies were unintended, as shown in figure 1 below.

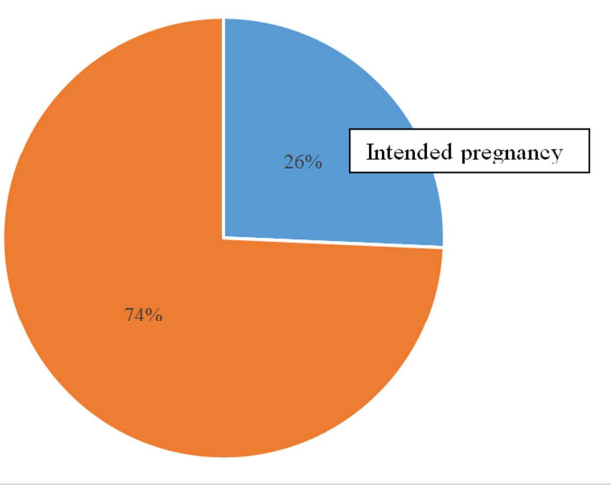

Figure 1. Whether the pregnancies were intended or not.
The key informants indicated that from their experience most of the teenage pregnancies were usually unintended although a few were actually intended.

The study farther revealed the reasons which led the teenagers to getting unintended pregnancies as the following: unprotected sex, ignorance on contraception methods, some thought they were on their safe days and lack of adequate knowledge on sex education (thought having sex the first time they would not get pregnant).

The key informants listed the following as the reason for the unintended pregnancies:

1. Lack of knowledge on sex matters.

2. Lack of education.

3. Sexual exploration.

4. Refusal by the husband on contraception use.

5. Peer pressure.

6. Cultural practices.

7. Young age.

The study also sought to determine the awareness on types of contraceptives among the respondents. The finding has been depicted on the figure 2 below.

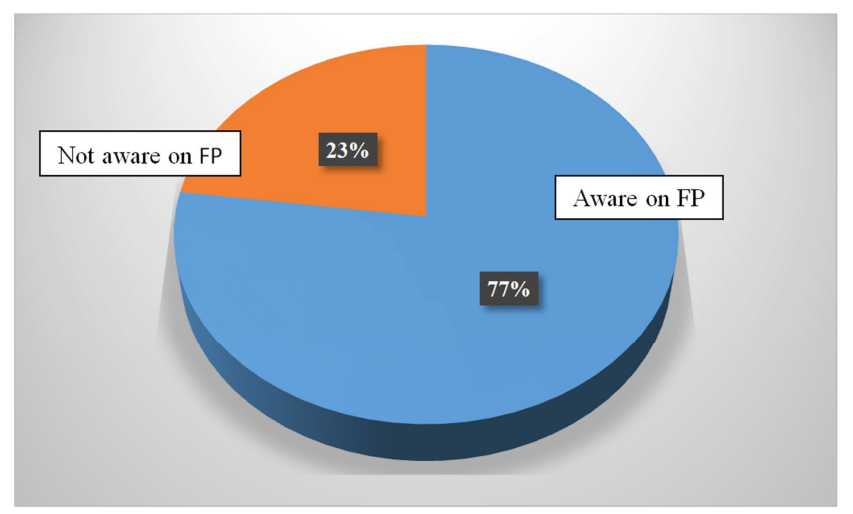

Figure 2. Awareness on types of contraception.

The study revealed that $77.1 \%$ (27) were awareness on types of contraception while $22.9 \%$ (8) had not. Indicating they were aware of emergency pill, combined oral contraceptive pills, 3 month injections, intrauterine device and condoms and implants. Farther indicating that $48.6 \%$ (17) of the respondents had ever used a method of Contraception and $51.4 \%$ (18) had never used any method of contraception.

The key informants indicated that some pregnant teenagers were aware of 3 month injections, Condoms use, and combined oral contraceptive pills as methods of contraception.

The reasons as to why use contraceptives were revealed as: protection from sexually transmitted diseases, avoidance of pregnancy, and spacing of children, boyfriend's initiative and peer pressure.

The key informants revealed avoidance of pregnancy and Protection from HIV/AIDS as reasons for contraception use among the pregnant teenagers.

Of the $49 \%$ who had never used contraception the study revealed lack of awareness, myths that it could kill the users and that they were not expecting to get pregnant. The key 
informants listed fear of being judged as being promiscuous and lack of awareness as the reasons for usage of contraception among the pregnant teenagers.
In addition the study revealed on awareness $17.1 \%$ (6) heard from the media, $40.1 \%$ (14) friends, $5.7 \%$ (2) hospital and $17.1 \%$ (6) school, as indicated in figure 3 below.

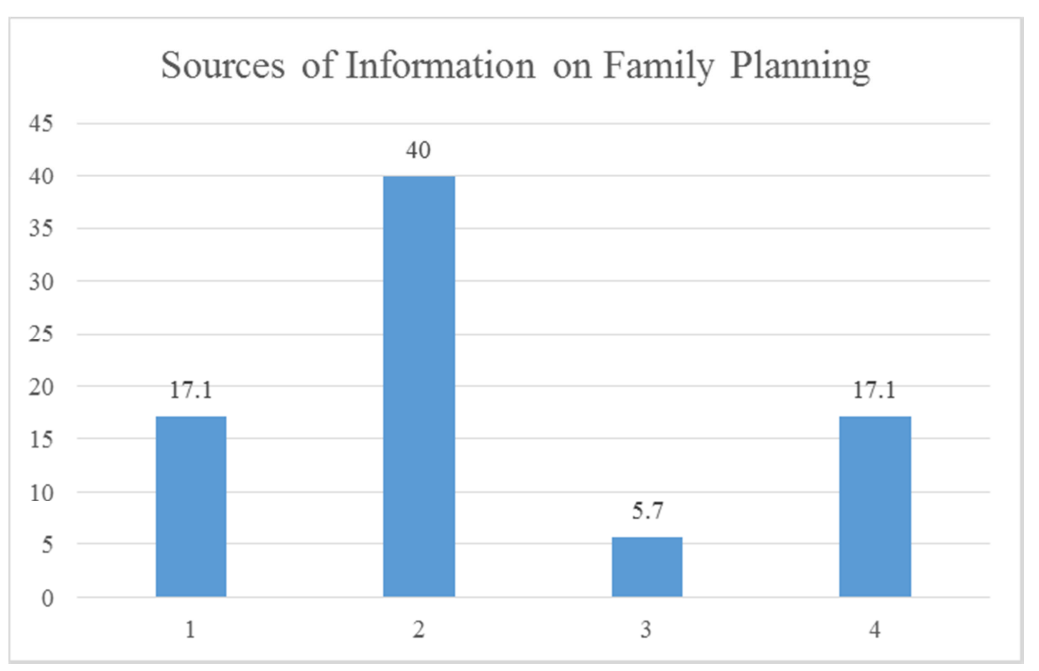

Figure 3. Sources of Information on Family Planning.

\subsection{Health Seeking Behaviors Among Pregnant Teenagers}

The study sought to find out the health seeking behavior among pregnant teenagers. All (100\%) the respondents sought medical attention in a medical facility prior. Of which were: Dispensary, sub-county Hospitals, Health-centers, and Clinics.

The key informants revealed a contradictory view that some of the pregnant teenagers especially from the interior parts, do not visit a medical facility unless when complications arose. Stating the fear of medical procedures and Practice of traditional beliefs as reasons.

The attendance to the antenatal clinic as indicated in figure 4 below.

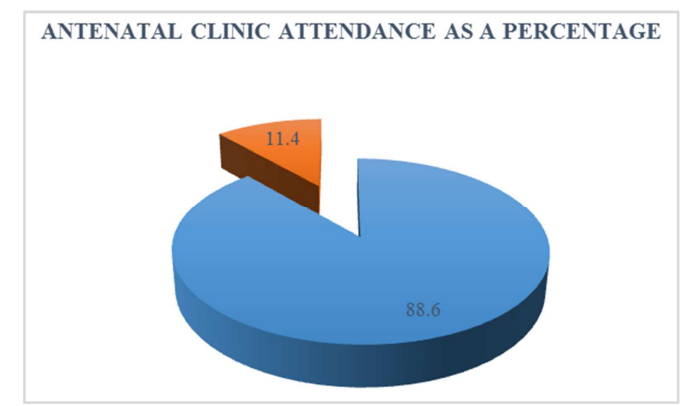

Figure 4. Attendance to ANC prior to attending Narok Level 5.

Though they had all sought medical attention prior only $11.4 \%$ ever attended ANC clinic.

The $(88.6 \%)$ who never attended the ANC clinic stated Lack of knowledge about the antenatal clinic as reasons for failure to attend the antenatal clinic. While key informants indicated the fear of being judged and Culture as reasons of failure.

The respondents' first antenatal visit were across $1^{\text {st }}$ Trimester, Late $2^{\text {nd }}$ Trimester, and $3^{\text {rd }}$ Trimester.

Upon Anemia screening for Antenatal profile only 3\% were positive while $97 \%$ were negative, as shown in figure 5 below.

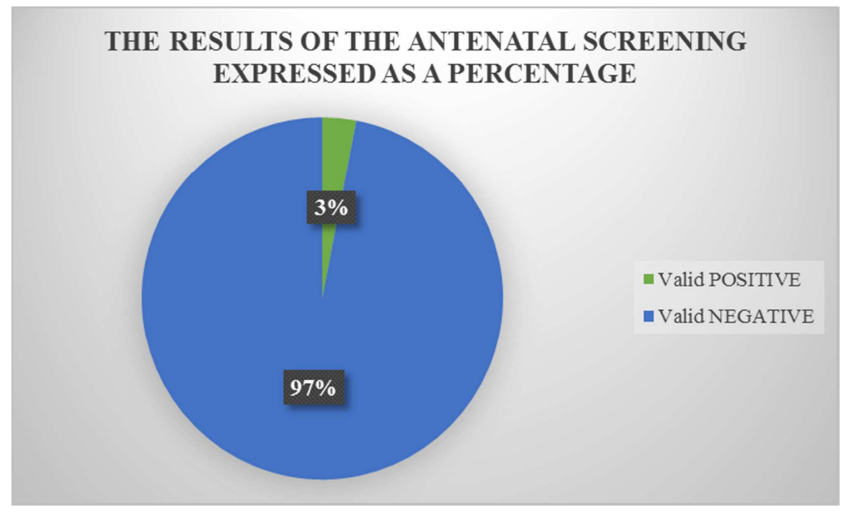

Figure 5. A pie-chart representing the results of the Antenatal screening.

Upon who determined when and where they attended for their health services were: Parents/ Guardians, Husband, Self, Siblings, and Doctors. The respondents' commended as "Good" the reception by medical attendants. For any medical bills Parents/ Guardians, Husband, Self, and Siblings paid for their health expenditures.

Majority $80 \%$ felt gender of their attending Clinician was not an issue of concern, while $20 \%$ were concern.

\section{Discussion}

\subsection{Health Related Challenges Faced by Pregnant Teenagers}

The study reveals that $60 \%$ (24) of the teenagers experienced health challenges while $40 \%$ (14) didn't experienced any health challenge during their course of pregnancy. Health challenges such as Hypertension, Anaemia, Urinary tract infection (UTI), Peptic ulcer disease (PUD) and 
sexually transmitted infections (STI). This is in agreement with [14] study that reported adolescent mothers aged between 10-19 years face higher risks of getting medical conditions such as eclampsia, puerperal endometritis and systemic infections than women aged 20-24. According to [15] the prevalence of depression is high during the perinatal period with worldwide estimates of $11-18 \%$ and estimates in low-income countries are as high as $30-50 \%$.

\subsection{Awareness on Modern Contraception Among Pregnant Teenagers}

Study indicated that $25.7 \%$ (9) pregnancies were intended while $74.3 \%$ (26) pregnancies were unintended. The key informants listed the following as the reason for the unintended pregnancies: Lack of knowledge on sex matters, Lack of education, Sexual exploration, Refusal by the husband on contraception use, Peer pressure, Cultural practices, Young age. While according to [16] age, education, place of residence, standards of living and husband education plays a major role in women having knowledge of all the modern methods of contraception. Unlike study by [17] reveals that fear and concern of family planning, myths, misconceptions, a method would render them infertile and partner approval.

Farther, the study revealed that $77.1 \%$ (27) were awareness on types of contraception while $22.9 \%$ (8) had not. Indicating they were aware of emergency pill, combined oral contraceptive pills, 3 month injections, intrauterine device and condoms and implants. Farther indicating that $48.6 \%$ (17) of the respondents had ever used a method of Contraception and 51.4\% (18) had never used any method of contraception. Similar to a study [18] showed that almost $21 \%$ students with knowledge of contraception are users, $82 \%$ of sexually active respondents were non-users while condom is the most common contraceptive method used. Also, $60 \%$ and $30 \%$ of respondents obtained knowledge about contraception from the media (TV/Radio) and peers (friends) respectively. However, almost $32 \%$ of the study participants thought contraceptives are for only adult married. Also [19] report indicate a substantially low proportion of women were aware of long-acting- or permanent methods such as implants, the intrauterine device (IUD), or sterilization - particularly male sterilization.

According to [20] cited marital status, partner consent and support, and religious beliefs strongly predicted usage.

\subsection{Health Seeking Behaviors Among Pregnant Teenagers}

The study showed that long- held family traditions was among the family level factors that influenced health seeking behaviors among pregnant teenagers. Which was also a factor [21]. According to [12]. indicates that educational intervention, significantly improved sexual abstinence and the knowledge of adolescents on pregnancy prevention among the adolescents. Also [22] indicated that adolescents living in rural areas, and especially those from households with a low socioeconomic status, find it difficult to reach health facilities due to the long distances and transport costs involved. This is coupled with long waiting times on arrival, owing to high demand at geographically dispersed health facilities. Also [19] report having an unwanted pregnancy is a significant risk factor for adverse health outcomes, including maternal mortality and morbidity. For women who decide to terminate a pregnancy, the main reasons for deaths vary, but the majority of deaths are as a result of complications from unsafe abortions.

\section{Conclusion}

1. The study revealed that pregnant teenagers attending Narok County Referral Hospital face quite a number of health related challenges during the course of their pregnancy. These findings are quite similar to other studies that have been done globally.

2. The study also revealed that the awareness level on modern contraception use was quite considerable high with over $77 \%$ among pregnant teenagers attending Narok County Referral hospital. However only 49\% practiced of those who were aware of contraception had actually used contraception

3. The study also revealed that the health seeking behavior among pregnant teenagers attending Narok County referral hospital was quite good with over $88 \%$ stating that they have actually attended antenatal clinic. The only thing wanting being that a considerable number wait until either the second or third trimester before attending antenatal clinic.

\section{Recommendation}

1. A thorough antenatal profiling of the pregnant teenagers as the best way to curb this problem. That will emphasise more focused antenatal profile compared to the general population (pregnant women who are not teenagers).

2. More emphasize on issues of sex education despite awareness being $77 \%$ among teenagers, aware on the consequences of participating in unprotected sex since it's over $40 \%$ instead of friends becoming major source.

3. Engage the community health workers encourage pregnant teenagers to start attending antenatal clinic as soon as they are pregnant rather than waiting for the second or third trimesters.

\section{References}

[1] World Health Organization -2018, Adolescent pregnancy.

[2] Kirchengast, S. (2016). Teenage Pregnancies: A Worldwide Social and Medical Problem. An Analysis of Contemporary Social Welfare Issues, 13.

[3] Kumar, M., Huang, K. Y., Othieno, C., Wamalwa, D., Madeghe, B., Osok, J. \& McKay, M. M. (2018). Adolescent pregnancy and challenges in Kenyan context: Perspectives from multiple community stakeholders. Global Social Welfare, $5(1), 11-27$. 
[4] Banspach, S., Zaza, S., Dittus, P., Michael, S., Brindis, C. D., \& Thorpe, P. (2016). CDC grand rounds: adolescencepreparing for lifelong health and wellness.

[5] World Bank Group. (2016). World development report 2016 : digital dividends. World Bank Publications.

[6] WHO. World health organization. (2014). Adolescent pregnancy. Fact sheet.

[7] Mathewos, S., \& Mekuria, A. (2018). Teenage pregnancy and its associated factors among school adolescents of Arba Minch town, southern Ethiopia. Ethiopian journal of health sciences, 28 (3), 287-298.

[8] Yakubu, I., \& Salisu, W. J. (2018). Determinants of adolescent pregnancy in sub-Saharan Africa: a systematic review. Reproductive Health, 15 (1), 15.

[9] Ochen, A. M., Chi, P. C., \& Lawoko, S. (2019). Predictors of teenage pregnancy among girls aged 13-19 years in Uganda: a community based case-control study. BMC Pregnancy and Childbirth, 19 (1), 211.

[10] Yakubu, I., Garmaroudi, G., Sadeghi, R., Tol, A., Yekaninejad, M. S., \& Yidana, A. (2019). Assessing the impact of an educational intervention program on sexual abstinence based on the health belief model amongst adolescent girls in Northern Ghana, a cluster randomised control trial. Reproductive health, 16 (1), 124.

[11] Alhassan, E. (2015). Early pregnancy of junior high school girls: causes and implications on academic progression in the Talensi District of the upper east region of Ghana.

[12] Yasmin, G., Kumar, A., \& Parihar, B. (2014). A study of socio-demographic factors of teenage pregnancy at a tertiary care centre. Hindu, 433, 64-43.

[13] National Conference of State Legislatures (2019) Teen Pregnancy Prevention.
[14] UNFPA. Girlhood not motherhood: Preventing adolescent pregnancy. New York: UNFPA; 2015.

[15] WHO, (2008). Adolescent pregnancy: World Health Organization. Available from http:www.who.int/maternalchildadolescent/documents/mpsnot es 21 r.pdf.

[16] Narzary, P. K. (2009). Knowledge and use of contraception among currently married adolescent women in India. Studies on Home and Community Science, 3 (1), 43-49.

[17] Ochako, R., Mbondo, M., Aloo, S., Kaimenyi, S., Thompson, R., Temmerman, M., \& Kays, M. (2015). Barriers to modern contraceptive methods uptake among young women in Kenya: a qualitative study. BMC public health, 15 (1), 118.

[18] Hagan junior, John \& Buxton, Christiana. (2012). Contraceptive Knowledge, Perceptions and Use among Adolescents in Selected Senior High Schools in the Central Region of Ghana. Sociological Research. 3. 10.5296/jsr.v3i2.2311.

[19] Mumah, J., Kabiru, C. W., Mukiira, C., Brinton, J., Mutua, M., Izugbara, C. O., \& Askew, I. (2014). Unintended pregnancies in Kenya: a country profile.

[20] Beson, P., Appiah, R., \& Adomah-Afari, A. (2018). Modern contraceptive use among reproductive-aged women in Ghana: prevalence, predictors, and policy implications. BMC women's health, $18(1), 157$.

[21] Shahabuddin, A., Nöstlinger, C., Delvaux, T., Sarker, M., Delamou, A., Bardají, A., \& De Brouwere, V. (2017). Exploring maternal health care-seeking behavior of married adolescent girls in Bangladesh: a social-ecological approach. PloS one, 12 (1), e0169109.

[22] Report of an adolescent health services barriers assessment: https://apps.who.int $>$ iris $>$ bitstream>handle $>9789290234302-$ eng. 